\title{
The hybrid approach for the surgical treatment of lone atrial fibrillation: One-year results employing a monopolar radiofrequency source
}

\author{
Mark La Meir ${ }^{1,4 \dagger}$, Sandro Gelsomino ${ }^{1,2^{*}+}$, Roberto Lorusso ${ }^{3}$, Fabiana Lucà ${ }^{1,2}$, Laurant Pison ${ }^{1}$, Orlando Parise ${ }^{1,2}$,
} Francis Wellens ${ }^{4}$, Gian Franco Gensini ${ }^{2}$ and Jos Maessen ${ }^{1}$

\begin{abstract}
Background: The hybrid technique combines a mono or bilateral epicardial approach with a percutaneous endocardial ablation in a single-step procedure. We present our early results with this technique employing a monopolar radiofrequency source through a right thoracoscopy in patients with lone atrial fibrillation (LAF).

Methods: Between June 2009 and December 2010 nineteen consecutive patients (mean 60.8 \pm 8.6 years, 84.2\% male) underwent right unilateral minimally invasive hybrid procedure for LAF at our Institution. Ten patients (52.6.6\%) had long-standing persistent AF while four (21.1\%) had persistent and five (26.3\%) paroxysmal AF. All patients were followed-up according the Heart Rhythm Society/European Heart Rhythm Association/European Cardiac Arrhythmia Society (HRS/EHRA/ECA) and Society of Thoracic Surgeon (STS) guidelines.

Results: There were neither early nor late deaths. It was possible to complete all the procedures as planned without any conversion to cardiopulmonary bypass. No patient died during the follow up. At one year, 7/19 (36.8\%) patients were in sinus rhythm with no episode of AF and off antiarrhythmic drugs (AAD). Time-related prevalence of postoperative AF peaked at 44.4\% (41.3-47.4) at two weeks, was 30.4\% (27.3-34.9) at three months, fell to $14.2 \%(11.6-18.1)$ by 6 months and was $13.3 \%(11.0-17.4)$ at 12 months Among patients with long-standing persistent (LSP) AF, 20\% (2/10) were in Sinus rythm and off AAD. One-year success rates were $50 \%(2 / 4)$ in persistent and 60\% (3/5) in paroxysmal AF. At 12 months estimated prevalence of antyarrhythmic drugs and Warfarin use were 26\% (22.4-33.1) and 48\% (37.2-53.2), respectively.

Conclusions: One year results combining the percutaneous endocardial with the right thoracoscopic epicardial technique were, in our experience, not satisfactory, particularly in patients with LSP and persistent AF. Our findings need to be confirmed by larger studies.
\end{abstract}

Keywords: Atrial fibrillation, Lone atrial fibrillation, Ablation, Minimally invasive

\section{Background}

Despite being more effective than percutaneous catheter ablation (PCA) [1-3], the MAZE operation failed to achieve widespread application as stand-alone procedure because of its complexity and invasiveness. Indeed, the Society for Thoracic Surgeons (STS) database [4] reported, in 2007, only 700 MAZE operations performed

\footnotetext{
* Correspondence: sandro.gelsomino@libero.it

${ }^{\dagger}$ Equal contributors

'University Hospital Maastricht, Maastricht, The Netherlands

${ }^{2}$ Careggi Hospital, Florence, Italy

Full list of author information is available at the end of the article
}

in patients with lone atrial fibrillation (LAF). In addiition, along with its suboptimal success rates, PCA showed a non-negligible incidence of major complications [3]. New technologies have allowed the creation of transmural lesions on a beating heart through alternative, less invasive incisions [5]. Nonetheless, results reported in the literature with these approaches are highly variable [6-8].

More recently, a sequential one-step surgical/catheterbased approach has been introduced showing satisfactory results in patients with persistent LAF [9]. This so-called hybrid procedure combines the advantages of PCA and

\section{Biomed Central}


video-assisted thoracoscopic epicardial procedures and it is expected to overcome the shortcomings of these techniques [10].

As originally described, the hybrid technique employs a bilateral thoracoscopic epicardial approach. We have recently introduced a less-invasive hybrid single-sided approach through a right thoracoscopy and, as far as we know, there are no reports in the literature about the effectiveness of this procedure.

Therefore, we present one-year results with minimally invasive hybrid-right thoracoscopic approach employing a monopolar radiofrequency (RF) source for the treatment of LAF.

\section{Methods}

\section{Patients}

Ethical Committee approval was waived according to the National law regulating observational retrospective studies (Dutch WMO law). However, all patients gave their informed consent to access their data for scientific purposes.

Between January 2008 and June 2010 nineteen consecutive patients underwent minimally invasive rightthoracoscopic hybrid ablation of LAF employing a monopolar RF source. LAF was defined as suggested by American College of Cardiology/American Heart Association/European Society of Cardiology (ACC/AHA/ ESC) Guidelines [11] and updated ESC Guidelines were followed to distinguish the type of $\mathrm{AF}$ and to score the AF-related symptoms (European Heart Rhythm Association [EHRA] score) [12]. Indication for minimally invasive surgery was based on the Heart Rhythm Society/ European Heart Rhythm Association/European Cardiac Arrhythmia Society (HRS/EHRA/ECA) Guidelines [13]. A trans-thoracic echocardiography (TTE) and a computed tomography (CT) scan were carried out preoperatively (pulmonary vein anatomy, coronary arteries) and potential candidates for the hybrid procedure underwent a lung function test (spirometry). Exclusion criteria were: 1) Presence of left atrial or left appendage thrombus at transesophageal echocardiography (TEE); 2) "Giant" left atrium (diameter $>6.5 \mathrm{~cm}$ ); 3) Associated coronary artery disease; 4) Previous pulmonary or cardiac surgery. Patient characteristics are shown in Table 1.

\section{Follow-up and assessment of $\mathrm{AF}$}

All patients were followed-up according to Heart Rhythm Society/European Heart Rhythm Association/European Cardiac Arrhythmia Society (HRS/EHRA/ECA) [13]. Main outcomes were also reported following the Society of Thoracic Surgeon (STS) guidelines [14]. After hospital discharge patients underwent 7-day Holter Monitoring (HM) which was repeated at 3 months, 6 months and 1 year. All patients reached 1-year follow up. Monitoring was carried
Table 1 Baseline Patient Characteristics $(n=19)$

\begin{tabular}{ll}
\hline Age & $61.2 \pm 8.6$ \\
\hline M/F & $16 / 3(84.2 / 15.8)$ \\
\hline BMI & $27.6 \pm 4.6$ \\
\hline Hypertension & $7(36.8)$ \\
\hline TIA/CVA & $1(5.2)$ \\
\hline Preoperative catheter ablation & $4(21.1)$ \\
\hline AF & $5(26.3)$ \\
\hline Flutter
\end{tabular}

Type of preoperative AF

\begin{tabular}{ll}
\hline Paroxysmal & $5(26.3)$ \\
\hline Persistent & $4(21.1)$ \\
\hline Long-standing persistent & $10(52.6)$ \\
\hline Prevalence of AF $(68 \% \mathrm{Cl})$ & \\
\hline Paroxysmal & $20.0(16.8-23.3)$ \\
\hline Persistent & $34.7(31.2-38.9)$ \\
\hline Long-standing persistent & $63.6(59.9-67.1)$
\end{tabular}

EHRA Score 4 [3-4]

Duration of preoperative AF (yrs.) 5 [3-8.5]

Antyarrhythmic Drugs

Amiodaron $2(10.5)$

Dysopiramide $1(5.3)$

Flecainide 6 (31.5)

Propaphenon $1(5.3)$

Sotalol $5(26.3)$

Electrical cardioversion 15 (78.9)

Previous Catheter Ablation

\begin{tabular}{ll}
\hline For AF & $6(31.5)$ \\
\hline For Atrial Flutter & $5(26.3)$ \\
\hline Preoperative Pacemaker & $2(10.5)$ \\
\hline Anticoagulant status & $16(84.2)$ \\
\hline Sodium Warfarin & $5(26.3)$ \\
\hline Aspirin & $47 \pm 11$ \\
\hline LAVI $\left(\mathrm{mL} / \mathrm{m}^{2}\right)$ & $49 \pm 20$ \\
\hline $\mathrm{LA}_{\mathrm{MAX}}\left(\mathrm{mL} / \mathrm{m}^{2}\right)$ & $30 \pm 15$ \\
\hline $\mathrm{A}_{\mathrm{MIN}}\left(\mathrm{mL} / \mathrm{m}^{2}\right)$ & $38 \pm 12$ \\
\hline $\mathrm{LA}(\%)$ & $5.0 \pm 0.5$ \\
\hline $\mathrm{LA} \mathrm{A-P}(\mathrm{cm})$ & $6.4 \pm 0.5$
\end{tabular}

Normal data were presented as mean \pm 1 Standard deviation (SD), non parametric data as Median and [Interquartile Range] and discrete data as percentage (\%).

Abbreviations: M/F: Male/Female; BMI: Body mass index; AF: Atrial fibrillation; Cl: Confidence Interval; EHRA: European Hear Rhythm Association; LAVI: (Biplane) Left Atrial Volume Index; LA MAx: Maximum Left Atrial Volume; LA $A_{M I N}$ : Minimum Left Atrial Volume; $L A_{E F}$ : Left Atrial emptying Fraction; LA A-P: Left Atrial Antero-Posterior Diameter; LA S-I : Left Atrial Superior-Inferior diameter.

out with an external loop recorder (Del Mar Reynolds, Spacelabs Healthcare, Issaquah, WA,USA) and analyzed with Lifescreen Software (Del Mar Reynolds, Spacelabs Healthcare, Issaquah, WA, USA). For analysis, three 
rhythms were considered postoperative AF: AF, atrial flutter or atrial tachycardia lasting more than $30 \mathrm{sec}$. In addition, all electrocardiograms (ECG) performed at the discretion of referring physicians/cardiologists during the first three months after surgery and between Holter examinations were included when patients had at least two records available for analysis. Each ECG and Holter was treated as discrete data (presence/absence of atrial fibrillation) to calculate AF estimated prevalence [14]. A total of 222 postoperative Holter/ECG data were retrieved.

\section{Echocardiography}

Echocardiography was performed preoperatively and at 3 month- and 12 month- follow-up appointments using a commercially available echocardiographic system (Philips iE33; Philips Medical Systems, Eindhoven, The Netherlands). All the parameters were analyzed "off-line" by an experienced echocardiographer (F.L.) using the Xcelera software (Philips Medical Systems Eindhoven, The Netherlands).

In the parasternal long-axis views LA maximum antero-posterior (A-P) diameter was measured. LA superior-inferior (S-I) diameter was measured from the mitral annular plane to the posterior wall of the LA in the apical 4-chamber view. In the apical 4-chamber view, LA maximum volume (LA max), at the end of LV systole, just before the opening of the mitral valve and LA minimum volume (LA min) at the end of LV diastole, just after the closure of the mitral valve, were measured [15]. LA emptying fraction $\left(\mathrm{LA}_{\mathrm{EF}}\right)$ was calculated as follows: (LA max-LA min/LA max) $\times 100$. LA maximum volume was also measured by biplane area-length method [16] and indexed to body surface area (LAVI). LARR was defined as a reduction in LAVI $\geq 15 \%$ at late follow up [17].

\section{Anticoagulation and antiarrhythmic therapy}

Antiarrhythmic drugs (AAD) were given postoperatively to all patients but, although we recommend discontinuing antyarrhythmics 3 months after ablation if the patients appears to be AF free, continued use is at the discretion of referring cardiologists.

Electrical cardioversion was not attempted for patients who remained in AF after the surgical procedure and was reserved for patients who were still in AF after 6 months.

Warfarin was administered on postoperative day II with INR target of 2.5 and stopped after 3 months if the Holter recording showed a sinus rhythm (SR) or patient had a low thromboembolic risk and a $\mathrm{CHADS}_{2}$ [cardiac failure, hypertension, age, diabetes, stroke (doubled)] score $<2$.

\section{Surgical technique}

The interventions were performed under general anesthesia with a double-lumen endotracheal tube for selective lung ventilation. The chest was entered in the second, fourth and sixth interspaces using respectively a 5-12-12 mm port. The technique was as previously reported [18].

High frequency stimulation (HFS) of the right vagal nerve at the level of the mediastinum and at the four major ganglionated plexi (GPS, [right superior GP, right inferior GP, left superior GP and left inferior GP)] was carried out and the vagal response on the atrioventricular node was recorded $(10 \mathrm{~V}, 1.5-\mathrm{ms}$ pulse width impulse at 1000 pulses per minute from a temporary external pacemaker [Oscor, Oscor INC., Palm Harbor, FL]) The isolation of pulmonary veins was performed with a Cobra ${ }^{\circledR}$ Adhere XL (Estech, Danville, Ca) temperaturecontrolled, monopolar radiofrequency system. The ablation catheter was pushed under the superior caval vein $(\mathrm{SCV})$ into the transverse sinus and placed behind the left atrial appendage (LAA) encircling the four PVs to create the box-lesion.

Before starting the ablation, the fat pad in the atrial groove was bluntly dissected to provide a better placement of the probe and enhance a higher penetration energy to destroy the GPs located inside this fat pad.

After creation of the box lesion the vagal response at level of GPS was tested again. The endpoint for ganglionated plexi (GP) ablation was the elimination of a vagal response to stimulation. In all patients this vagal response could no longer be induced with HFS, except for the right inferior GP which, being located outside the box lesion was not to ablated in any patient.

A left femoral vein puncture was made and a HIS bundle catheter (St Jude Medical, Inc, Minnetonka, MN, USA) and a coronary sinus (CS) catheter (Medtronic, Inc, Minneapolis, MN, USA) were placed under fluoroscopic guidance. Through the right femoral vein, a single trans-septal puncture was made using TEE and fluoroscopy and a long sheath $8 \mathrm{~F}$ (SLO, St. Jude Medical Daig Division, Inc., Minnetonka, MN, USA) was advanced into the LA. The patient was heparinzed to keep the activated clotting time $>300$ seconds. During rapid ventricular pacing from the HIS catheter, contrast was injected through the long sheath in order to visualize PVs and the LA. PVs were mapped with a suitably sized circular mapping catheter (Lasso, Biosense Webster, Inc, Diamond. Bar, CA, USA) placed at the ostium of the PVs.

In all patients epicardial pacing and endocardial recordings were utilized to demonstrate entrance and exit block; entrance block was defined as failure to capture the PVs during pacing from the left atrium at $18 \mathrm{~V}$ and 1.5-ms pulse width and the absence of pulmonary vein potentials (PVPs) seen on the Lasso catheter. Exit 
block was defined by failure to capture the left atrium during the pacing from the PVs and by failure to capture when pacing from each dipole of the Lasso catheter with an output of $10 \mathrm{~mA}$ and $2.0 \mathrm{~ms}$ pulse width.

We identified the conduction gaps from the endocardium which were closed endocardially with a $3.5 \mathrm{~mm}$ tip catheter (ThermoCool, Biosense Webster, Inc., Diamond. Bar, CA, USA) through the sheath in the LA. The precise location of the linear lesions was visualized with the Cobra $^{\circledR}$ Adhere XL (Estech, Danville, Ca) in situ and using fluoroscopy. Gaps in linear lesions were defined as low amplitude and fragmented or narrowly split double atrial potentials.

In case of AF persistence, a left isthmus line was made endocardially from the mitral annulus towards the CS employing the ThermoCool catheter (ThermoCool, Biosense Webster, Inc., Diamond. Bar, CA, USA) The endpoint of ablation of the mitral isthmus was the bidirectional block which was achieved when the following criteria were met: 1) proximal-to-distal activation sequence along the CS catheter after pacing lateral to the line in the LA appendage; 2) Late activation on the opposite side after pacing on the septal side of the line through the CS; 3) widely separated local double potentials along the whole length of the ablation line. Finally, if the patient had a history of typical right atrial flutter or this arrhythmia became apparent during the procedure, we performed a cavo-tricuspid isthmus line (CTI) endocardially. The endpoint was bidirectional block and the presence of widely separated double potentials along the whole length of the ablation line.

\section{Statistical analysis}

Normal values were expressed as mean \pm one standard deviation (SD), non-normal values as median and interquartile range (IQR) and categorical variables as percentages. Student $t$, Wilcoxon and McNemar's tests were employed where appropriate.

We analyzed all the intermittent data available in terms of time-related prevalence of AF [14] with a multiphase hazard decomposition method [19]. Prevalence of AF was presented as percentage with asymmetric $68 \%$ confidence obtained with the bootstrap percentile method [20].

Analyses of prevalence of AF do not account for antiarrhythmic medications. Prevalence of antiarrhythmic medication use was estimated by mixed modeling based on medication use at each follow-up assessment. With the same method we estimated the prevalence of Warfarin use at the time of each follow-up. Finally, the use of electrical cardioversion was analyzed as a repeated event and is presented as cumulative incidence [21].

Statistical analysis was performed using SPSS release 12.0 (SPSS, Chicago, IL, USA) and Curve Expert
Professional release1.0.1 (D.G. Hyams, Chattanooga, TN, USA). $P$ values less than 0.05 were considered significant.

\section{Results}

None of the patients showed entrance and/or exit block after the epicardial ablation. Seventeen patients had at least one PV not isolated, which needed an endocardial touch-up (Table 2). After completing endocardial PV isolation the entire population had a conduction delay $>200 \mathrm{~ms}$. in the posterior LA but no patient had complete block.

Three patients (15.7\%) underwent mitral isthmus line and in all cases a complete block was achieved. A cavotricuspid isthmus (CTI) line was carried out in two patients (10.5\%) with successful bidirectional block. All surgical procedures were completed as planned without any conversion to cardiopulmonary bypass. Median operative time was 216 minutes (IQR 132-391). There were neither early deaths nor complications during the postoperative course. Median Intensive care unit (ICU) stay was 6.9 hours [IQR 4.0-14.0] and median inhospital length of stay was 3.6 days [2.7-4.3].

No patient died during the follow up. There was a significant improvement in median EHRA (European Hear Rhythm Association) score at follow up (1[IQR 1-2], $p<0.001$ vs. baseline). At one year, 7/19 (36.8\%) patients were in sinus rhythm and off-AAD. Furthermore, 63.1\% (12/19), patients were free from AF, AFL or AT $>30 \mathrm{~s}$ but still under antiarrhythmic therapy $(p=0.1)$.

Time-related prevalence of postoperative AF was $44.4 \%(41.3-47.4)$ at two weeks, $30.4 \%(27.3-34.9)$ at three months, $14.2 \%(11.6-18.1)$ at 6 months and $13.3 \%$ (11.0-17.4) at 12 months (Figure 1A). Among patients with long-standing persistent AF, 20\% (2/10) were in SR and off-AAD. One-year success rates were $50 \%(2 / 4)$ in persistent and $60 \%(3 / 5)$ in paroxysmal AF. At 12 months the estimated prevalence of antyarrhythmic drugs (Figure 2A) was 26\% (22.4-33.1). AAD-prevalences by AF type were $38.1 \%$ (34.3-43.4) for long-standing

Table 2 Lesions set

\begin{tabular}{ll}
\hline Left atrium & $19(100)$ \\
\hline Right PVs Isolation & $19(100)$ \\
\hline Left PVs Isolation & $19(100)$ \\
\hline Inferior line & $19(100)$ \\
\hline Roof line & $3(15.7)$ \\
\hline Isthmus lesion & $17(88.4)$ \\
\hline Endocardial gaps closure & $2(10.5)$ \\
\hline Right atrium & $19(100)$ \\
\hline Cavo-tricuspid isthmus line
\end{tabular}

Abbreviations. PVs: Pulmonary Veins. 

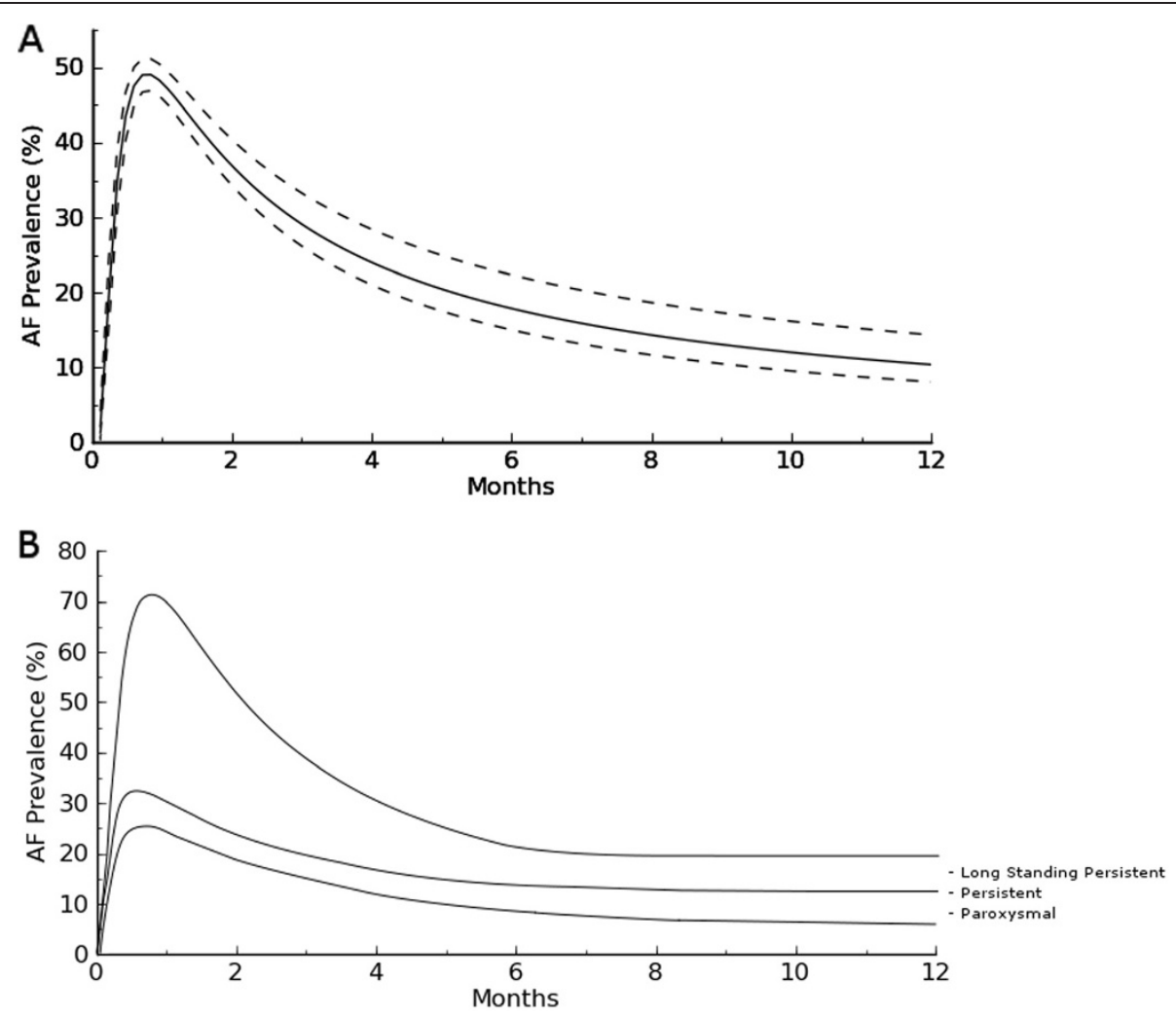

Figure 1 A. Time-related prevalence of Atrial Fibrillation after hybrid procedure. B. Time-related prevalence of Atrial Fibrillation by AF type.

persistent, $26.3 \%(22.2-30.7)$ for persistent and $14.9 \%$ (9.9-17.8) for paroxysmal AF. Finally, time-related prevalence of Warfarin (Figure 2B) at 1 year was $48.2 \%$ (44.2-52.2). This figure was $52.5 \%$ (48.8-55.2) in longstanding persistent, $35.3 \%(32.5-39.2)$ in persistent and $19.4 \%$ (16.3-23.3) in paroxysmal AF. The cumulative incidence of electrical cardioversion was $0.05 /$ patient.

\section{LA function and remodeling}

Table 3 shows postoperative echocardiographic data. At 3 month- follow-up biplane LAVI was reduced by $16 \%$ $(p=0.05)$. It further decreased but not significantly at 1 year $(p=0.09)$. Based on the cut-off value $(\geq 15 \%$ reduction in LAVI) LARR occurred in $47.3 \%(n=9)$ of patients. LA $\mathrm{EF}_{\mathrm{EF}}$ increased not significantly at 3 month$(p=0.6)$ and at 12 -month- $(p=0.56)$ controls. Finally, LA diameters decreased significantly at 3 months (LA A-P, $p=0.02$; LA S-I $p=0.03$ ) whereas at one year there was a further reduction which did not reach statistical significance (LA A-P, $p=0.73$; LA S-I $p=0.81$ ).

\section{Discussion}

Minimally invasive surgical epicardial thoracoscopic approaches have gained a growing popularity but data regarding their efficacy are controversial [6-9,22-25]. The hybrid approach combines, in one step, a thoracoscopic epicardial ablation with a PCA procedure $[9,26]$. The surgeon, through a thoracoscopy, can isolate the pulmonary veins and the posterior wall of the LA whereas the endocardial "step" offers the possibility of evaluating the endpoints of the ablation and it gives the opportunity to add an endocardial "touch-up" in case of incomplete epicardial PVs isolation. In addition, the electrophysiologist (EP) can make lesions in regions which cannot be reached epicardially. Moreover, this technique may potentially decrease the complication rate of both surgical and catheter ablation procedures. Indeed, from the point of view of the surgeon, the risk of post-operative arrhythmias is reduced since ablation lines and lesion set can be controlled endocardially and the risk of injury is lower, since the EP can make lesions in areas which cannot be easily reached by the surgeon.

On the other hand, from the EP point of view, there is no risk of phrenic nerve and esophageal injury because these structures can be protected by the surgeon and the possibility of tamponade is low since the pericardium is open. Furthermore, by reducing the total number of endocardial ablations the risk of embolism is potentially reduced [27].

We present our one-year results with minimally invasive hybrid-right thoracoscopic approach employing a 

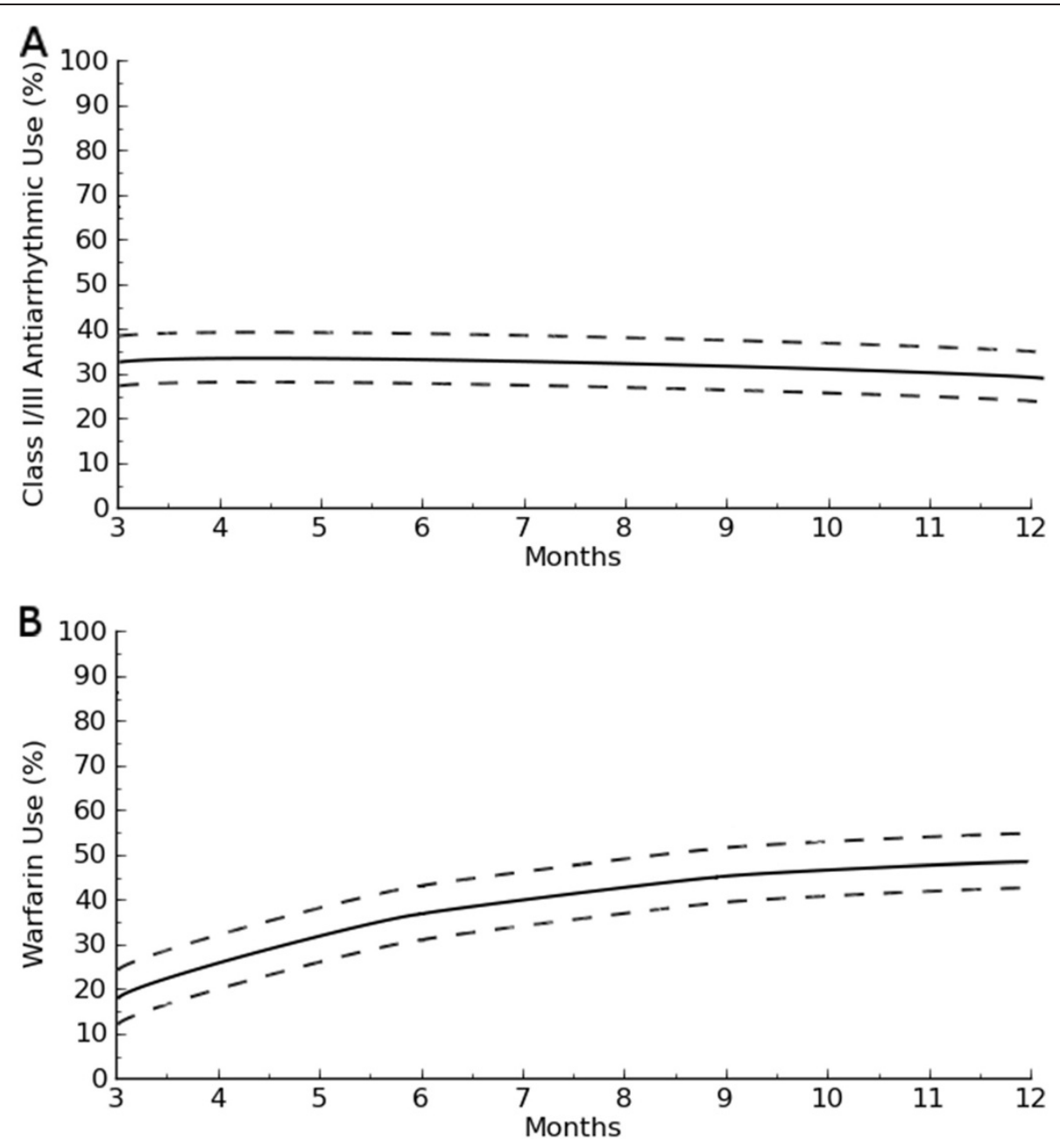

Figure 2 A. Prevalence of class I/III anti-arrhythmic use after hybrid procedure. B. Prevalence of Warfarin use hybrid procedure.

monopolar radiofrequency (RF) source for the treatment of LAF. Little information exists in the literature about the hybrid technique $[10,28]$ and, to the best of our knowledge, no data exist on the right monolateral monopolar hybrid approach.

The monolateral right-thoracoscopic approach could theoretically reduce the rates of complications (bleeding, pulmonary complications) and significantly shorten patients' recovery time. Nonetheless, only monopolar devices can be used through the right-thoracoscopy because of the lack of maneuverability of bipolar clamps (which can hamper the orientation of the probe and constrain the variety of achievable lesion sets when employed from the right side) but many concerns have been raised regarding the ability of monopolar devices to create transmural lesion with bidirectional conduction block on the beating heart [29].

This technique demonstrated, in our experience, a high degree of safety with no major complications and no major thromboembolic events detected during the follow up period. Nonetheless, at one year only 36.8\%(7/ 19) patients were in SR and off-AAD. Among patients with long-standing persistent AF, 20\% (2/10) were in SR and off-AAD. One-year success rates were $50 \%(2 / 4)$ in persistent and 60\% (3/5) in paroxysmal AF. Furthermore, at 12 months, the estimated prevalence of antyarrhythmic drugs was $26 \%$ (38.1\% in LSP, 26.3\%in persistent and $14.9 \%$ in paroxysmal AF). The incidence of patients without recurrent AF but with AAD was not significantly lower compared with patients off-AAD $(p=0.1)$ although this data must be interpreted taking into account the small number of patients in the study. Therefore, this limitation does not allow us to draw any conclusion about the role of AAD in the development of AF recurrence following minimally invasive surgery.

However, the success rate, in this series, was lower than published papers employing monopolar devices [30] and it might be explained by the high number of patients with long-standing persistent (LSP) and persistent AF which represent $73.6 \%$ of our cohort. 
Table 3 LA remodeling

\begin{tabular}{|c|c|}
\hline LAVI $(\mathrm{mL} / \mathrm{m}$ & \\
\hline 3 months & $45 \pm 10$ \\
\hline 12 months & $40 \pm 11$ \\
\hline$p$ & 0.09 \\
\hline \multicolumn{2}{|c|}{$\mathrm{LA}_{\text {Max }}\left(\mathrm{mL} / \mathrm{m}^{2}\right)$} \\
\hline 3 months & $46 \pm 15$ \\
\hline 12 months & $45 \pm 13$ \\
\hline$p$ & 0.7 \\
\hline \multicolumn{2}{|c|}{$\mathrm{LA}_{\mathrm{Min}}\left(\mathrm{mL} / \mathrm{m}^{2}\right)$} \\
\hline 3 months & $27 \pm 10$ \\
\hline 12 months & $25 \pm 8$ \\
\hline$p$ & 0.86 \\
\hline \multicolumn{2}{|l|}{$\mathrm{LA}_{\mathrm{EF}}(\%)$} \\
\hline 3 months & $41 \pm 14$ \\
\hline 12 months & $43 \pm 14$ \\
\hline$p$ & 0.56 \\
\hline \multicolumn{2}{|l|}{ LA A-P (cm) } \\
\hline 3 months & $3.9 \pm 0.4^{*}$ \\
\hline 12 months & $3.7 \pm 0.4$ \\
\hline$p$ & 0.73 \\
\hline \multicolumn{2}{|l|}{ LA S-I (cm) } \\
\hline 3 months & $5.9 \pm 0.6^{*}$ \\
\hline 12 months & $5.8 \pm 0.6$ \\
\hline$p$ & 0.81 \\
\hline
\end{tabular}

Normal data were presented as mean \pm 1 Standard deviation (SD). *Significance vs. Baseline. Abbreviations: LAVI: (Biplane) Left atrial volume index; LAMax: Maximum left atrial volume; LAMin: minimum left atrial volume; $L_{E F}$ : Left atrial emptying fraction; LA A-P: Left atrial antero-posterior diameter; LA S-I: Left atrial antero-posterior diameter.

Indeed, LSP and persistent AF may be considered to be advanced stages of the arrhythmia characterized by significant changes in the atrial tissue and muscle (substrate modification) that leads to chaotic electrical activity. Thus, these patients might need more areas in the heart ablated than in the monolateral approach and they might benefit much more from procedures which increase the likelihood that ablation lines are transmural although this aspect may be addressed by the EP who can complete any line by focused endocardial applications. Indeed, in our experience, the incidence of incomplete, non trans-mural gap lesions was high, none of the patients showed entrance and/ or exit block after the epicardial ablation and,after completing PV isolation endocardially, all patients had a conduction delay $>200 \mathrm{~ms}$. in the posterior LA but no patient had complete block.

With this current knowledge we have stopped using monopolar devices for the surgical treatment of AF, even for patients where a monolateral approach may have a potential advantage i.e. in case of reduced pulmonary function. In these patients we now perform a monolateral approach from the right or left side, depending on the wish to close the LAA, using bipolar devices ${ }^{10}$ and isolating the opposed PVs endocardially with RF energy.

Finally, at latest follow up only $47.3 \%$ of patients experienced LARR and there was no significant improvement in LAVI and LAEF. Due to the small number of patients, we could not compare echocardiographic data by AF type. However, again, the high percentage of subjects with LSP or persistent AF reflects a greater extent of substrate modifications and atrial structural remodeling and this could explain the lack of LARR. Indeed, all five patients with paroxysmal AF showed a $\geq 15 \%$ decrease in LAVI.

\section{Limitations of the study}

This study has some limitations which have to be pointed out. The small patient population and the short follow-up do not allow us to draw definite conclusions. Larger series with long-term follow up are needed. Second, only a small number of patients in this series underwent right-sided and isthmus lesions and this might have influenced the results. Third, our study did not compare the hybrid right thoracoscopic approach with the hybrid bilateral thoracoscopic approach to evaluate the real impact of these different techniques on outcome of LAF patients and to evaluate whether the excision of the LAA, besides the management for prevention of thromboembolic events, might have a contribute to different rhythm outcome. Furthermore we did not compare PCA with surgical thoracoscopic approaches. However, all these aspects will be the subjects of ongoing studies.

Fourth, while data regarding postoperative AF prevalence were obtained from a large number of observations and this allowed us to compare prevalence by AF type, we could not evaluate LAVI, LAEF and LA diameters in any subgroup of patients.

Finally, atrial function was studied employing only the emptying fraction and neither pulsed-wave Doppler nor Tissue Doppler Imaging (TDI) nor LA strain were employed, which would have given more detailed information about LA function after AF surgical ablation. All these aspects deserve further investigations

\section{Conclusions}

One year results combining the percutaneous endocardial with the right thoracoscopic epicardial technique were, in our experience, not satisfactory, particularly in patients with LSP and persistent AF. This approach might still be considered a possible alternative to PCA in selected patients with paroxysmal lone atrial fibrillation and impaired pulmonary function referred to surgery 
when the LAA excision/ligation is not deemed necessary. Our findings need to be confirmed by larger studies.

\section{Abbreviations}

LAF: Lone Atria Fibrillation; PCA: Percutaneous Catheter Ablation; RF: Radiofrequency; LSP: Long-standing persistent; EHRA score: European Heart Rhythm Society score; SCV: Superior caval vein; ICV: Inferior Caval Vein; LAA: Left Atrial Appendage; GP: Ganglionated plexi; PVs: Pulmonary Veins; CTI: Cavo-tricusoid isthmus (lesions); CS: Coronary sinus; SR: Sinus Rhythm EP: Electrophysuologist; LARR: Left Atrial Reverse Remodeling; LAVI: (Biplane) Left atrial volume index; LAMax: Maximum left atrial volume;

LAMin: Minimum left atrial volume; LA $A_{E F}$ : Left atrial emptying fraction; LA A-P: Left atrial antero-posterior diameter; LA S-I: Left atrial antero-posterior diameter.; IQR: Interquartile Range; TEE: Transesophageal Echocardiography; TTE: Transthoracic echocardiography.

\section{Competing interests}

Dr La Meir has been consultant/advisor for Atricure and Estech. Other co-authors do not have any conflict of Interest.

\section{Authors' contribution}

MLM Research design, drafting, approval Equal Contributors. SG Research design, drafting, approval Equal Contributors. RL Research design, drafting approval. FL Article Collection, Research design, drafting, approval. LP Critical Revision, drafting, approval. OP Article Collection, Research design, drafting, approval. FW Critical Revision, drafting, approval. GFG Drafting, Final revision and approval of the manuscript. JM Final revision and final approval of the manuscript. All authors read and approved the final manuscript.

\section{Acknowledgments}

We gratefully acknowledge Mr. James Douglas who provided medical writing services on behalf of University Hospital Maastricht. We thank Mrs. Mr. Pol Chambille and Monique de Jong for their help in acquisition of data.

\section{Author details}

${ }^{1}$ University Hospital Maastricht, Maastricht, The Netherlands. ${ }^{2}$ Careggi Hospital, Florence, Italy. ${ }^{3} \mathrm{Civic}$ Hospital Brescia, Brescia, Italy. ${ }^{4}$ University Hospital Brussels, Brussels, Belgium.

Received: 28 February 2012 Accepted: 16 June 2012 Published: 19 July 2012

\section{References}

1. Cox JL, Ad N: New surgical and catheter-based modifications of the Maze procedure. Semin Thorac Cardiovasc Surg 2000, 12:68-73.

2. Shen J, Bailey M, Damiano RJ: Surgery for lone atrial fibrillation. Present State Art: Innov 2000, 4:248-255.

3. Cappato R, Calkins H, Chen SA, Davies W, lesaka Y, Kalman J, Kim YH, Klein G, Natale A, Packer D, Skanes A, Ambrogi F, Biganzoli E: Updated worldwide survey on the methods, efficacy, and safety of catheter ablation for human atrial fibrillation. Circ Arrhythm Electrophysiol 2010, 3:32-38.

4. Society of Thoracic surgeons National Adult Cardiac surgery Database. http://www.sts.org/national-database.

5. Sales VL, McCarthy PM: Minimally invasive surgery for atrial fibrillation. Tex Heart Inst J 2010, 37:660-661.

6. Klinkenberg TJ, Ahmed S, Ten Hagen A, Wiesfeld AC, Tan ES, Zijlstra F, Van Gelder IC: Feasibility and outcome of epicardial pulmonary vein isolation for lone atrial fibrillation using minimal invasive surgery and high intensity focused ultrasound. Europace 2009, 11:1624-1631.

7. Pruitt JC, Lazzara RR, Ebra G: Minimally invasive surgical ablation of atrial fibrillation: the thoracoscopic box lesion approach. J Interv Card Electrophysiol 2007, 20:83-87.

8. Beyer $E$, Lee $R$, Lam BK: Point: minimally invasive bipolar radiofrequency ablation of lone atrial fibrillation: early multicenter results. J Thorac Cardiovasc Surg 2009, 137:521-526.

9. Mahapatra S, LaPar DJ, Kamath S, Payne J, Bilchick KC, Mangrum JM Ailawadi G: Initial experience of sequential surgical epicardial- catheter endocardial ablation for persistent and long-standing persistent atrial fibrillation with long-term follow-up. Ann Thorac Surg 2011, 91:1890-1898.
10. Pison L, La Meir M, van Opstal J, Blaauw Y, Maessen JG, Crijns HJ: Hybrid Thoracoscopic Surgical and Transvenous Catheter Ablation of Atrial Fibrillation. J Am Coll Cardiol 2012, 60:54-61

11. Fuster V, Rydén LE, Cannom DS, Crijns HJ, Curtis AB, Ellenbogen KA, Halperin JL, Le Heuzey JY, Kay GN, Lowe JE, Olsson SB, Prystowsky EN, Tamargo JL, Wann S, Smith SC Jr, Jacobs AK, Adams CD, Anderson JL, Antman EM, Halperin JL, Hunt SA, Nishimura R, Ornato JP, Page RL, Riegel B, Priori SG, Blanc JJ, Budaj A, Camm AJ, Dean V, Deckers JW, Despres C, Dickstein K, Lekakis J, McGregor K, Metra M, Morais J, Osterspey A, Tamargo JL, Zamorano JL: ACC/AHA/ESC 2006 guidelines for the management of patients with atrial fibrillation: a report of the American College of Cardiology/American Heart Association Task Force on Practice Guidelines and the European Society of Cardiology Committee for Practice Guidelines (Writing Committee to Revise the 2001 Guidelines for the Management of Patients With Atrial Fibrillation). J Am Coll Cardiol 2006, 48:854-890.

12. Camm AJ, Kirchhof P, Lip GY, Schotten U, Savelieva I, Ernst S, Van Gelder IC, Al-Attar N, Hindricks G, Prendergast B, Heidbuchel H, Alfieri O, Angelini A, Atar D, Colonna P, De Caterina R, De Sutter J, Goette A, Gorenek B, Heldal M, Hohloser SH, Kolh P, Le Heuzey JY, Ponikowski P, Rutten FH, ESC Committee for Practice Guidelines, Vahanian A, Auricchio A, Bax J, Ceconi C, Dean V, Filippatos G, Funck-Brentano C, Hobbs R, Kearney P, McDonagh T, Popescu BA, Reiner Z, Sechtem U, Sirnes PA, Tendera M, Vardas PE, Widimsky P, Document Reviewers, Vardas PE, Agladze V, Aliot E, Balabanski T, Blomstrom-Lundqvist C, Capucci A, Crijns H, Dahlöf B, Folliguet T, Glikson M, Goethals M, Gulba DC, Ho SY, Klautz RJ, Kose S, McMurray J, Perrone Filardi P, Raatikainen P, Salvador MJ, Schalij MJ, Shpektor A, Sousa J, Stepinska J, Uuetoa H, Zamorano JL, Zupan I: Guidelines for the management of atrial fibrillation: the Task Force for the Management of Atrial Fibrillation of the European Society of Cardiology (ESC). Europace 2010, 12:1360-1420.

13. European Heart Rhythm Association (EHRA); European Cardiac Arrhythmia Scoiety (ECAS); American College of Cardiology (ACC); American Heart Association (AHA); Society of Thoracic Surgeons (STS), Calkins H, Brugada J, Packer DL, Cappato R, Chen SA, Crijns HJ, Damiano RJ Jr, Davies DW, Haines DE, Haissaguerre $M$, lesaka $Y$, Jackman $W$, Jais $P$, Kottkamp $H$, Kuck KH, Lindsay BD, Marchlinski FE, McCarthy PM, Mont JL, Morady F, Nademanee K, Natale A, Pappone C, Prystowsky E, Raviele A, Ruskin JN, Shemin RJ: HRS/EHRA/ECAS expert consensus statement on catheter and surgical ablation of atrial fibrillation: recommendations for personnel, policy, procedures and follow-up. Heart Rhythm 2007, 4:816-861.

14. Shemin RJ, Cox JL, Gillinov AM, Blackstone EH, Bridges CR: Workforce on evidence-based surgery of the society of thoracic surgeons. workforce on evidence-based surgery of the society of thoracic surgeons. Guidelines for reporting data and outcomes for the surgical treatment of atrial fibrillation. Ann Thorac Surg 2007, 83:1225-1230

15. Kuppahally SS, Akoum N, Burgon NS, Badger TJ, Kholmovski EG, Vijayakumar S, Rao SN, Blauer J, Fish EN, Dibella EV, Macleod RS, McGann C, Litwin SE, Marrouche NF: Left atrial strain and strain rate in patients with paroxysmal and persistent atrial fibrillation: relationship to left atrial structural remodeling detected by delayed enhancement-MRI. Circ Cardiovasc Imaging 2010, 3:231-239.

16. Jiamsripong P, Honda T, Reuss CS, Hurst RT, Chaliki HP, Grill DE, Schneck SL, Tyler R, Khandheria BK, Lester SJ: Three methods for evaluation of left atrial volume. Eur J Echocardiogr 2008, 9:351-355.

17. Tops $L F$, Delgado V, Bertini M, Marsan NA, Den Uijl DW, Trines SA, Zeppenfeld K, Holman E, Schalij MJ, Bax JJ: Left atrial strain predicts reverse remodeling after catheter ablation for atrial fibrillation. J Am Coll Cardiol 2011, 57:324-331.

18. La Meir M, De Roy L, Blommaert D, Buche M: Treatment of lone atrial fibrillation with a right thoracoscopic approach. Ann Thorac Surg 2007 83:2244-2245.

19. Blackstone EH, Naftel DC, Turner ME Jr: The decomposition of time-varying hazard into phases, each incorporating a separate stream of concomitant information. J Am Stat Assoc 1986, 81:615-624.

20. Efron B, Tibshirani RJ: An introduction to the bootstrap. New York: Chapman and Hall/CRC; 1998.

21. Gillinov AM, Bhavani S, Blackstone EH, Rajeswaran J, Svensson LG, Navia JL, Pettersson BG, Sabik JF 3rd, Smedira NG, Mihaljevic T, McCarthy PM, 
Shewchik J, Natale A: Surgery for permanent atrial fibrillation: impact of patient factors and lesion set. Ann Thorac Surg 2006, 82:502-513.

22. Edgerton JR, Edgerton ZJ, Weaver T, Reed K, Prince S, Herbert MA, Mack MJ: Minimally invasive pulmonary vein isolation and partial autonomic denervation for surgical treatment of atrial fibrillation. Ann Thorac Surg 2008, 86:35-38.

23. Li H, Li Y, Sun L, Liu X, Xu C, Han J, Meng X: Minimally invasive surgical pulmonary vein isolation alone for persistent atrial fibrillation: preliminary results of epicardial atrial electrogram analysis. Ann Thorac Surg 2008, 86:1219-1225.

24. Cheema FH, Weisberg JS, Khalid I, Roberts HG Jr: Warm beating heart, robotic endoscopic Cox. Warm beating heart, robotic endoscopic Cox-cryomaze: an approach for treating atrial fibrillation. Ann Thorac Surg 2009, 87:966-968.

25. Sirak J, Jones D, Schwartzman D: The five-box thoracoscopic maze procedure. Ann Thorac Surg 2010, 90:986-989.

26. La Meir M, De Roy L, Gourdin M: A Hybrid approach for treatment of patients with atrial fibrillation with radiofrequency catheters. In Hybrid and minimally invasive cardiac intervention. Edited by Maessen J, Crijns $\mathrm{H}$. Turin: Minerva Medica; 2010:9-13.

27. Sauren LD, la Meir M, de Roy L, Pison L, van der Veen FH, Mess WH, Crijns $\mathrm{HJ}$, Maessen JG: Increaesd number of cerebral emboli during percutaneous endocardial pulmonary vein isolation versus a thoracoscopic epicardial approach. Eur J Cardiothorac Surg 2009, 36:833-837.

28. Krul SP, Driessen AH, Zwinderman AH, van Boven WJ, Wilde AA, de Bakker JM, de Groot JR: Thoracoscopic video-assisted pulmonary vein antrum isolation, ganglionated plexus ablation and periprocedural confirmation of ablation lesions. First results of a hybrid surgical-electrophysiological approach for atrial fibrillation. Circ Arrhythm Electrophysiol 2011, 4:262-270.

29. van Brakel TJ, Bolotin G, Salleng KJ, Nifong LW, Allessie MA, Chitwood WR Jr. Maessen JG: Evaluation of epicardial microwave ablation lesions: histology versus electrophysiology. Ann Thorac Surg 2004, 78:1397-1402.

30. Nasso G, Bonifazi R, Del Prete A, Del Prete G, Lopriore V, Bartolomucci F, Calafiore AM, Speziale G: Long-term results of ablation for isolated a trial fibrillation through a right minithoracotomy: Toward a rational revision of treatment protocols. J Thorac Cardiovasc Surg 2011, 142:41-46.

doi:10.1186/1749-8090-7-71

Cite this article as: La Meir et al:: The hybrid approach for the surgical treatment of lone atrial fibrillation: One-year results employing a monopolar radiofrequency source. Journal of Cardiothoracic Surgery 2012 7:71.

\section{Submit your next manuscript to BioMed Central and take full advantage of:}

- Convenient online submission

- Thorough peer review

- No space constraints or color figure charges

- Immediate publication on acceptance

- Inclusion in PubMed, CAS, Scopus and Google Scholar

- Research which is freely available for redistribution 